\title{
RELATIONSHIP BETWEEN SOME IMMUNOLOGICAL FACTORS AND TYPE 2 DIABETES MELLITUS IN IRAQI PATIENTS
}

\author{
MOHAMMED SALIH AL-JANABY ${ }^{1}$, MOHAMMED QAIS AL-ANI ${ }^{1}$, MARRIB N RASHEED ${ }^{2}$ \\ ${ }^{1}$ Department of Biology, College of Science, University of Anbar, Ramadi, Iraq. ${ }^{2}$ Department of Genetic Engineering, Institute of Genetic \\ Engineering and Biotechnology, University of Baghdad, Iraq. Email: drmohammedqais1975@gmail.com
}

Received: 26 March 2018, Revised and Accepted: 18 April 2018

\section{ABSTRACT}

Objective: To determine whether elevated levels of the inflammatory markers interleukin 6 (IL-6), interleukin 8 (IL-8) and insulin - like growth factor- 1 are associated with development of type 2 DM in Iraqi sample.

Methods: A total number of 150 samples in this study, including 75 diabetes mellitus patients and 75 healthy people (control) This study was conducted from August 2016 to February 2017. All samples were collected from Anbar city, Iraq. Serum concentrations of IL-6, IL-8 and IGF. were determined using a commercially available enzyme-linked immune sorbent assay (ELISA).

Results: The results of the present study showed that there was a difference in the mean values of IL-6, IL-8 and IFG between the group of patients with type 2 diabetes and the control group The results showed a negative correlation between IL- 6 and IL-8, while the correlation between IL-6 and IGF and between IL -8 and IGF was showed positive correlation

Conclusion: Elevated levels of IL-6 and IL-8 predict the development of type 2 DM. These data support a possible role for inflammation in diabetogenesis. Type 2 diabetes as well as pre-diabetic states, including impaired fasting glucose and impaired glucose tolerance, are associated cross-sectionally with altered circulating levels of IGF-I . decline in the levels of IGF-I dependent on duration of diabetes in non insuline dependent diabetic patients.

Keywords: IL-6, IL-8, IGF., Diabetes mellitus, Iraqi Patients.

(C) 2018 The Authors. Published by Innovare Academic Sciences Pvt Ltd. This is an open access article under the CC BY license (http://creativecommons. org/licenses/by/4. 0/) DOI: http://dx.doi.org/10.22159/ajpcr.2018.v11i6.25881

\section{INTRODUCTION}

Type 2 diabetes (T2D) is a major global health problem affecting 415 million people ( 215 million of men and 199 million of women). It is considered that this number will rise to 642 million in 2040. Of these, $90-95 \%$ of cases are T2D [1].

This statistics show the dangerous of D2M compare with cancer because when we look into the statistics of cancer incidence and mortality in the last few years reported by International Agency for Research on Cancer, an estimated 14.1 million new cancer cases were registered and 8.2 million cancer-related deaths occurred in 2012, whereas in 2008, 12.7 million and 7.6 million were estimated, respectively [2].

Discovery of interleukins (ILs) began in the 1950s, but it took about 2 decades to precise structure and function of them to be identified. The first described members of this family were IL-1, interferon, and nerve growth factors. Nowadays, more than 35 types of ILs have been identified [3].

Cytokines are small proteins initially thought to be components of the immune system but have been found to play a much broader role in physiology [4].

The cytokines that are produced during inflammatory processes, and that participate in them, are stimulators of the production of acute phase proteins. These inflammation-associated cytokines include IL6 , IL-1 $\beta$, tumor necrosis factor- $\alpha$, interferon- $\gamma$, transforming growth factor- $\beta$, and, possibly, IL-8. They are produced by a variety of cell types, but the most important sources are macrophages and monocytes at inflammatory sites [5].
Hyperinsulinism seen in metabolic syndrome (MetS) and type 2 DM can induce rise in inflammatory markers including IL- 6 and C-reactive protein. High levels of IL-6 have been reported to be associated with insulin resistance in adipocytes, hepatocytes, and myocytes [6].

Apart from different cells that are involved in immune response, cytokines are supposed to be a major component of the immune system. They are considered chemical communicators of different parts of the immune system and consist of ILs, interferons, and growth factors. Complement system is also a chemical part of the immune system that is made up of about 25 proteins that work together to destroy antibody covered organisms or remove them through other cellular components of the immune system. Each component of the complement system activates one another leading to a cascade that remove the invaders. They also act as a part of the inflammatory response system [3].

Insulin-like growth factor (IGF)-I is a peptide hormone that shares nearly $50 \%$ of amino acid sequence homology with proinsulin, and like insulin, is composed of an alpha and a beta chain connected by disulfide bonds. Most IGF-I in circulation is produced by the liver, with IGF-I levels largely regulated by GH through a negative feedback mechanism. However, other factors may also affect hepatic IGF-I synthesis including nutrition (e.g., caloric intake and protein consumption), insulin, and inflammatory cytokines. The effects of IGF-I are primarily mediated by its binding to the IGF-IR. The IGF-IR, like the insulin receptor, is comprised two membrane-spanning alpha subunits and two intracellular beta subunits. Insulin and IGF-I can bind to each other's receptors, though with low affinity, and only at high (non-physiological) levels. However, the function of IGF-II in adults is not well understood. The binding of both IGF-I and insulin to their respective receptors results in the activation of the tyrosine kinase domain present in these receptors and post- 
receptor phosphorylation of members of the insulin receptor substrate (IRS) family. The insulin receptor preferentially phosphorylates IRS-1, whereas IGF-IR preferentially phosphorylates IRS-2, which may partly correspond to the differences in their activity. IGF-I is a more potent mitogen with stronger antiapoptotic activity than insulin, and plays a major role in regulating cell replication, differentiation, and survival, whereas insulin has stronger metabolic activity than IGF-I [7].

In the last few years, increasing evidence has suggested that IGF-I may have a role in both glucose homeostasis and cardiovascular disease. Animals with liver-specific IGF-I gene deletion are characterized by hyperinsulinemia and skeletal muscle insulin resistance. Treatment of these animals with recombinant human IGF-I caused a reduction in insulin levels and an increase in insulin sensitivity. Clinical studies performed on normal subjects, patients with extreme insulin resistance, and patients with type 1 or T2D have shown that recombinant IGF-I administration significantly lowered blood glucose and increased insulin sensitivity. Supporting the concept that IGF-I promotes insulin action, a recent study concluded that low concentrations of IGF-I in the circulation increased the risk for developing T2D considerably during a 4.5-year follow-up [8].

IL-6 is homodimer cytokine, its size 19-26 kd produced from many cells in the body such as endothelial cells, fibroblasts, and monocytes (macrophages) [3].

The IL-6 is a multifunctional cytokine whose actions include modulation of proliferation, differentiation, and maturation of hemopoietic progenitors and other cell lineages, growth regulation of certain carcinoma cell lines, and control of cellular metabolic activities. It is becoming increasingly clear that IL-6 modulates both local and systemic inflammation and immunity [7].

Overexpression of IL-6 has been implicated in the pathology of a number of diseases including multiple myeloma, rheumatoid arthritis, Castleman's disease, psoriasis, and postmenopausal osteoporosis. Hence, selective antagonists of IL- 6 action may offer therapeutic benefits. IL- 6 is a member of the family of cytokines that include IL-11, leukemia inhibitory factor, oncostatin $\mathrm{M}$, cardiotrophin-1, and ciliary neurotrophic factor. Like the other members of this family, IL-6 induces growth or differentiation through a receptor system [9].

The peripheral resistance to insulin and the development of DM2 have also been associated with an increase of IL- 6 by adipose tissue. High levels of IL- 6 increase the production of free fatty acid (FFA) and contribute to the blockage of the insulin pathway signaling, making tissues less responsive to insulin action. IL-6 has several roles related to the regulation of lipid metabolism including the inhibition of lipoprotein lipase activity and triglycerides deposition. IL-6 can also have an important role in blocking the insulin pathway on livers and muscles through SOCS proteins [10].

IL-8 is considered an important chemokine in periodontal disease. This cytokine is produced by a variety of cells and may function in concert with other members of the cytokine family to regulate the host's innate responses. Specifically, this cytokine attracts leukocytes from the periphery to the sites of infection and activates them to become phagocytes. This suggests that IL-8 is indispensable for neutrophil migration and function. Neutrophil function is not only important in acute infections but also plays a major role in chronic inflammatory disorders such as periodontitis, atherosclerosis, psoriasis, rheumatoid arthritis, inflammatory bowel disease, diabetes, and cancer [11].

The aim of this study was to find the relationship between some immunological factors include IL-6, IL-8, and IGF and type 2 diabetes mellitus (T2DM) in blood of Iraqi patients.

\section{METHODS}

This study was conducted from August 2016 to February 2017 on a total number of 150 subjects including 75 diabetes mellitus patients and 75 control group. All samples were collected from Anbar city, Iraq.
Table 1: LSD of IL-6, IL-8, and IGF in type 2 diabetes mellitus patients

\begin{tabular}{lllll}
\hline LSD & & & & \\
\hline p value & $\begin{array}{l}\text { Mean } \\
\text { difference (I-J) }\end{array}$ & Group & & \\
\hline 0.032 & $-935.95238^{*}$ & $70-79$ & $40-49$ & IL-6 Pg $\backslash \mathrm{ml}$ \\
0.027 & $-643.20098^{*}$ & $60-69$ & $50-59$ & \\
0.012 & $-990.36905^{*}$ & $70-79$ & & \\
0.027 & $643.20098^{*}$ & $50-59$ & $60-69$ & \\
0.032 & $935.95238^{*}$ & $40-49$ & $70-79$ & \\
0.012 & $990.36905^{*}$ & $50-59$ & & \\
\hline
\end{tabular}

IL: Interleukin, IGF: Insulin-like growth factor, LSD: Least significance difference

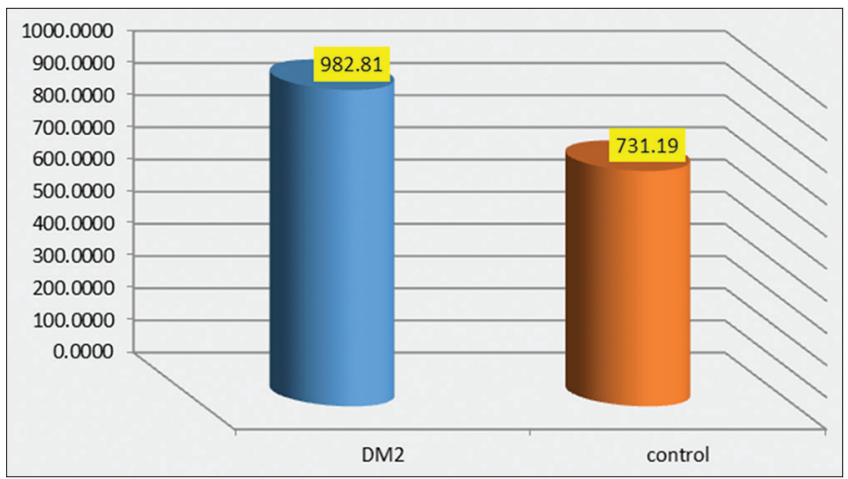

Fig. 1: Level of interleukin-6 in patients with type 2 diabetes mellitus and control group

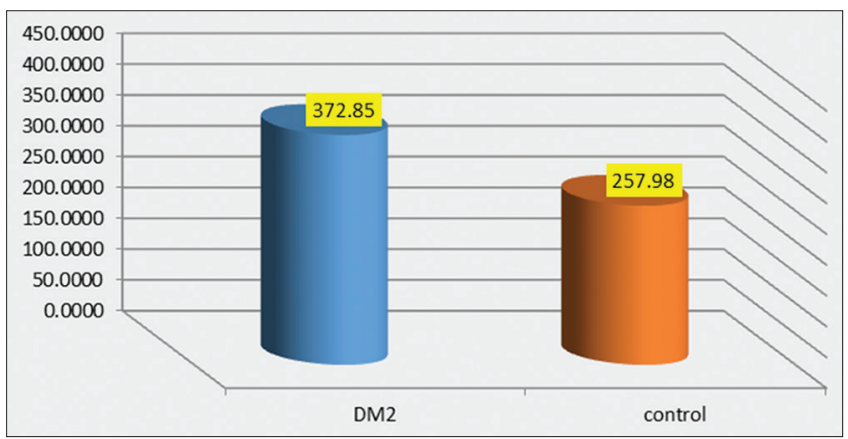

Fig. 2: Level of interleukin-8 in patients with type 2 diabetes mellitus and control group

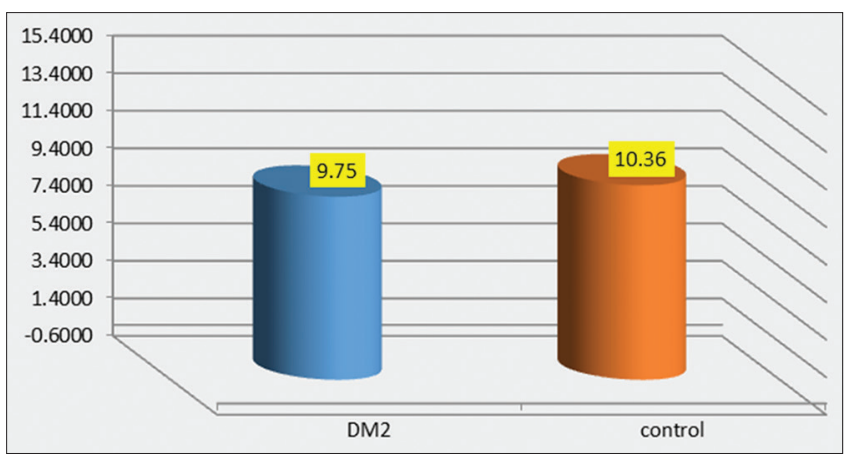

Fig. 3: Level of insulin-like growth factor in patients with type 2 diabetes mellitus and control group

Collected blood samples $4 \mathrm{~mL}$ were taken patients and control group, placed into Gel tubes, left around $15 \mathrm{~min}$ at room temperature, and it is centrifuged at $2000 \times \mathrm{g}$ for $10 \mathrm{~min}$ to get the serum, to be used while in the measurement of IL- 6 , IL-8, and IGF. 
Estimation of IL-6, IL-8, and IGF

The concentrations of IL-6, IL-8, and IGF were determined using a commercially available enzyme-linked immune sorbent assay (ELISA) based on biotin double antibody sandwich technology, ELISA kit (Gen Asia) GA-E0130HM, GA-E0129HM, and GA-E5454HM, respectively, according to the manufacturer's instructions.

\section{RESULTS}

Effect of IL-6, IL-8, and IGF on T2DM patients

The results of the present study showed that there was a difference in the mean values of IL- 6 between the group of patients with T2D and the control group where the values of the means $\pm(982.81,731.19) \mathrm{Pg} / \mathrm{ml}$, respectively, and there was an increase in the total leukocyte count (LSD) values in the group of patients $(\mathrm{p}<0.05)$ (Fig. 1)

The results of the present study showed that there was a difference in the mean values of IL- 8 between the group of patients with T2D and the control group where the values of the means $\pm(372.85,257.98) \mathrm{ng} / \mathrm{L}$, respectively, and there was an increase in the LSD values in the group of patients $(\mathrm{p}<0.05)$ (Fig. 2).

The results of the present study showed that there was a difference in the mean values of IGF between the group of patients with T2D and the control group where the values of the means $\pm(9.75,10.36) \mathrm{ng} / \mathrm{ml}$,

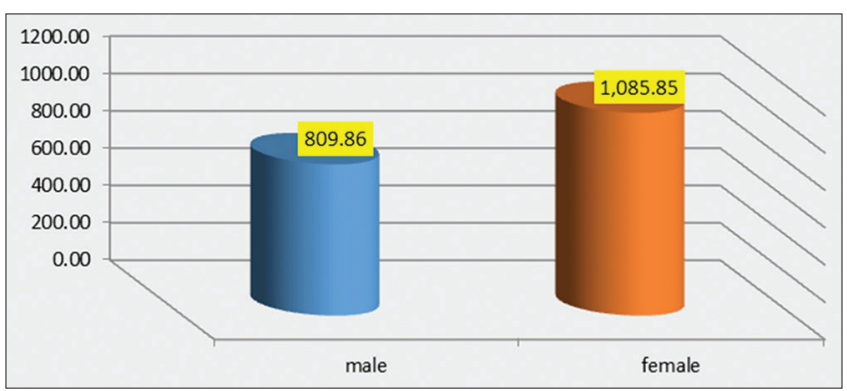

Fig. 4: Level of interleukin- 6 in male and female patients with type 2 diabetes mellitus

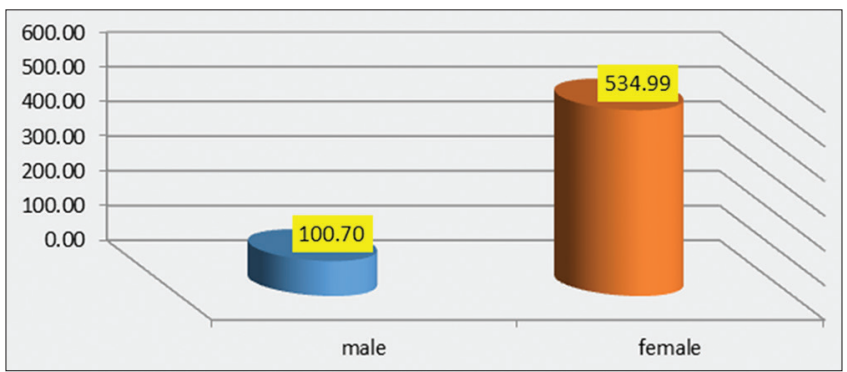

Fig. 5: Level of interleukin-8 in male and female patients with type 2 diabetes mellitus

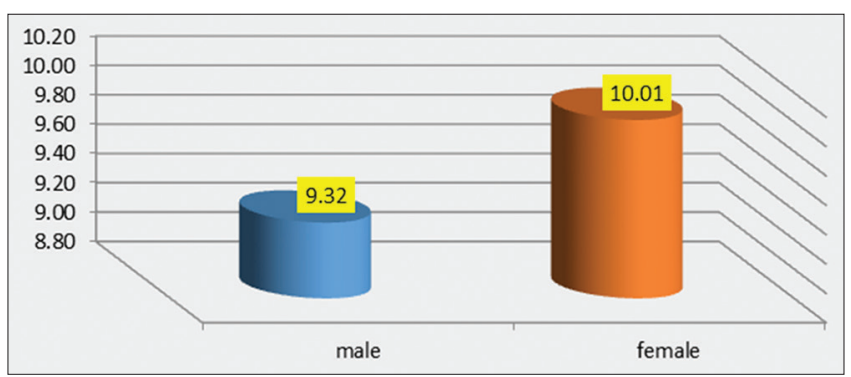

Fig. 6: Level of insulin-like growth factor in male and female patients with type 2 diabetes mellitus respectively, and there was an increase in the LSD values in the group of patients $(\mathrm{p}<0.05)$ (Fig. 3)

\section{Effect of sex on IL-6, IL-8, and IGF in T2DM patients}

The results of the present study showed that there was a difference in the mean values of IL- 6 between male and female patients with T2D where the values of the means $\pm(809.86,1085.85) \mathrm{pg} / \mathrm{ml}$, respectively, and there was an increase in the LSD values in the group of patients $(\mathrm{p}<0.05)$ (Fig. 4).

The results of the present study showed that there was a difference in the mean values of IL- 8 between male and female patients with T2D where the values of the means $\pm(100.70,534.99) \mathrm{ng} / \mathrm{L}$, respectively, and there was an increase in the LSD values in the group of patients $(p<0.05)$ (Fig. 5).

The results of the present study showed that there was a difference in the mean values of IGF between male and female patients with T2D where the values of the means $\pm(9.32,10.01) \mathrm{ng} / \mathrm{ml}$, respectively, and there was an increase in the LSD values in the group of patients $(\mathrm{p}<0.05)$ (Fig. 6).

Effect of age on IL-6, IL-8, and IGF in T2DM patients

The results of the study showed a significant difference in the values of IL-6, IL-8, and IGF in patients compared to control group Table 1.

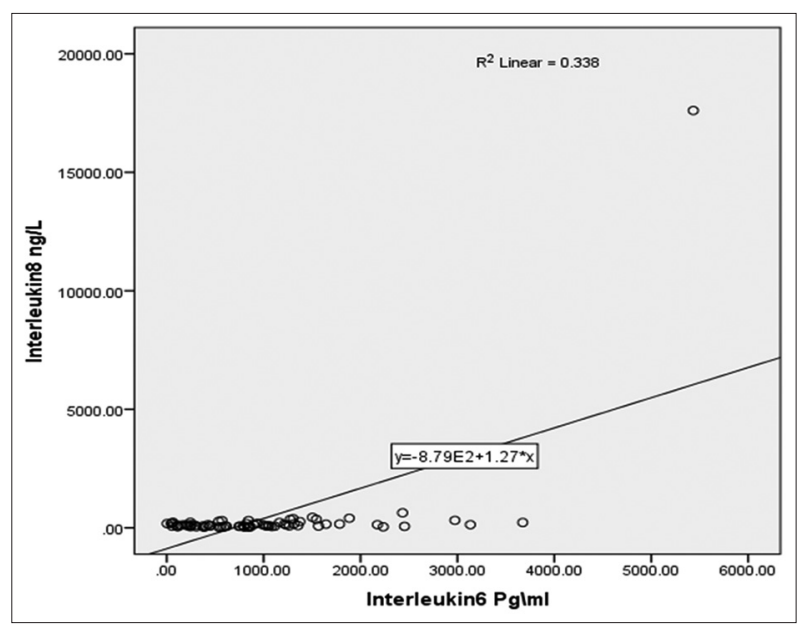

Fig. 7: Correlation between interleukin (IL)-6 and IL-8 in type 2 diabetes mellitus patients

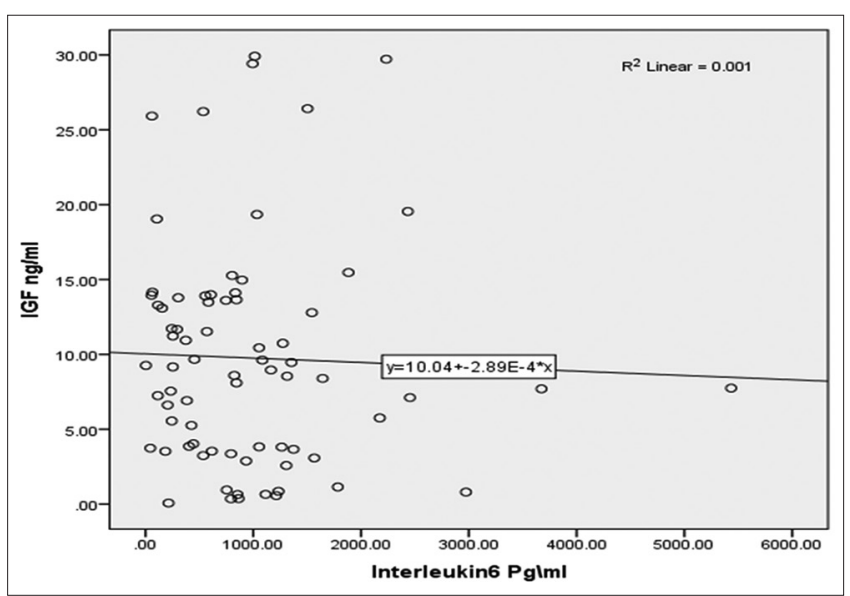

Fig. 8: Correlation between interleukin- 6 and insulin-like growth factor in type 2 diabetes mellitus patients 


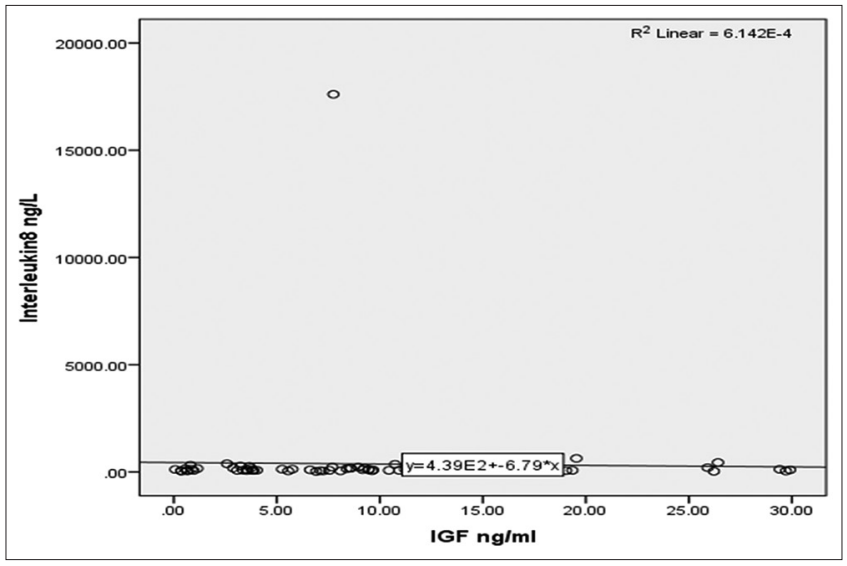

Fig. 9: Correlation between interleukin-8 and insulin-like growth factor in type 2 diabetes mellitus patients

Correlation between IL-6, IL-8, and IGF in T2D mellitus patients The results showed a negative correlation between IL- 6 and IL- 8 and Y 8.79 as shown in Fig. 7, while the correlation between IL-6 and IGF was Y 10.04 as shown in Fig. 8, showed positive correlation between IL-8 and IGF, and the value of Y 4.39 was Fig. 9.

\section{DISCUSSION}

Diabetes mellitus type 2 (DM 2) is a metabolic disease caused by resistance to insulin and is characterized by the abnormal metabolism of glucose, proteins, and lipids. In fact, type $2 \mathrm{DM}$ is an inflammatory disease, and inflammatory cytokines are involved in its pathogenesis [12].

Inflammatory processes are associated with the development of insulin resistance, mainly in skeletal muscle, decreased insulin secretion by pancreatic beta cells and development of vascular changes in individuals with metabolic disorder. The linking among cytokines, insulin resistance, and DM 2 has been intensively studied and, apparently, multiple mechanisms are involved, including modulation of lipolysis, alteration of glucose uptake by adipose tissue, and indirectly through increase in FFA levels that block the insulinsignaling pathway [13].

The main objective of this study was to investigate the role of inflammatory biomarkers in the pathophysiology of T2DM. The highest levels of the proinflammatory cytokines IL- 6 and chemokines such as IL-8 play a critical role in driving and inflammatory milieu since they mediate the arrival of inflammatory cells to the site of both acute and chronic inflammation [14].

Several studies have investigated the effect of IGF-I on insulin sensitivity and its relation to T2D. Large longitudinal studies, including the National Health and Nutrition Examination Survey (NHANES) III, reported a higher risk of insulin resistance, MetS, and T2D in subjects with low IGF-I serum concentrations or low IGF-I-to-IGFBP-3 ratios [16].

In this study, we showed that high levels of inflammatory cytokines IL-6 and IL-8 were present in DM2 compare to control, this agree with previous studies which showed that IL-6 and IL-8 in DM2 subjects (36), high level of IL-6 was among cases than among controls [16].

This study showed increased concentrations of serum IL- 6 and IL-8 and reduced serum IGF levels as it showed in positive correlation among both IL-6 and IL-8 with IGF, this agree with other previous study on retinopathy of prematurity [17]. IL-6, IL-8, and IGF were high serum levels in women in this study compared with men.

\section{CONCLUSIONS}

This study concludes that there is a rise in the levels of IL- 6 and IL-8 in the serum of people with T2D compared to the health of the disease. This suggests that there are immune differences between people with diabetes and those without diabetes. The decrease in serum IGF value in diabetic patients compared with healthy people may explain part of the metabolic disorder in growth because diabetes is a metabolic disorder also not just an immune disorder.

\section{AUTHOR'S CONTRIBUTIONS}

Mohammed S and Maarb N evaluation of IL- 6 and IL-8 and IGF, blood sample collection, and statistical analysis was done by Mohammed Q. All authors contributed ideas and thought to the writing of this paper.

\section{CONFLICTS OF INTEREST}

The authors declared that they have no conflicts of interest.

\section{REFERENCES}

1. Malenica M, Šilar M, Dujić T, Bego T, Semiz S, Škrbo S, et al. Importance of inflammatory markers and IL-6 for diagnosis and follow up of patients with type 2 diabetes mellitus. Med Glas (Zenica) 2017; $14: 169-75$

2. Al-Biati HA, Sahib AS, Ismail SH. Effects of metformin and glibenclaimide combination in Iraqi obese patients with metabolic syndrome. Int J Pharm Pharm Sci 2014;6:501-3.

3. Razavi GS, Allen T. Emerging role of interleukins in cancer treatment. Immunome Res 2015;S2:1745-7580.

4. Erta M, Quintana A, Hidalgo J. Interleukin-6, a major cytokine in the central nervous system. Int J Biol Sci 2012;8:1254-66.

5. Gabay C. Interleukin-6 and chronic inflammation. Arthritis Res Ther 2006;82:S3

6. Reddy NM, Reddy NR, Jamil K. Spicy anti-cancer spices: A review. Int J Pharm Pharm Sci 2015;7:1-6.

7. Swapnil N. Rajpathak, Gunter MJ, Wylie-Rosett J, Ho YFG, Robert C. Kaplan, Muzumdar R et al. The role of insulin-like growth factor-I and its binding proteins in glucose homeostasis and type 2 diabetes. Diabetes Metab Res Rev 2009;25:3-12.

8. Sesti G, Vatrano M, Sciacqua A, Succurro E, Cardellini M, Lauro R. Plasma concentration of IGF-I is independently associated with insulin sensitivity in subjects with different degrees of glucose tolerance. Diabetes Care 2005;28:132-7.

9. Simpson RJ, Hammacher A, Smith DK. Interleukin-6: Structurefunction relationships. Protein Sci 1997;6:6929-955.

10. Biffl WL, Moore EE, Moore FA. Interleukin-6 in the injured patient marker of injury or mediator of inflammation? Ann Surg 1996;224:647-64.

11. Benakanakere MR, Finoti LS, Tanaka U, Grant GR. Investigation of the functional role of human Interleukin- 8 gene haplotypes by CRISPR/ Cas9 mediated genome editing. Sci Rep 2016;6:31180.

12. Tavangar A, Khozeimeh F, Ghoreishian F, Boroujeni MA. Serum level of Interleukin-8 in subjects with diabetes, diabetes plus oral lichen planus, and oral lichen planus: A biochemical study. Dent Res J (Isfahan) 2016;13:413-8.

13. Shih YL, Ho KT, Tsao CH, Chang YH, Shiau MY, Huang CN, et al. Role of cyotkines in metabolism and type 2 diabetes mellitus. Int $\mathrm{J}$ Biomed Lab Sci 2013;2:1-6.

14. Gupta S, Maratha A, Siednienko J, Natarajan A, Gajanayake T, Hoashi S, Miggin S. Analysis of inflammatory cytokine and TLR expression levels in Type 2 Diabetes with complications. Sci Rep 2017:7:7633.

15. Friedrich N, Spielhagen C, Thuesen B, Wallaschofksi H, Jørgensen T, Linneberg A, et al. The association between IGF-I and insulin resistance. Diabetes Care 2012;35:768-73.

16. Pradhan AD, Manson JE, Rifai N, Buring JE, Ridker PM. C-reactive protein, interleukin 6 , and risk of developing type 2 diabetes mellitus. JAMA 2001;286:327-34

17. Akdis M, Aab A, Altunbulakli C, Azkur K, Costa RA, Crameri R, et al. Interleukins (from IL-1 to IL-38), interferons, transforming growth factor $b$, and TNF-a: Receptors, functions, and roles in diseases. J Allergy Clin Immunol 2016;138:984-1010. 